\title{
Transient meiotic arrest maintained by DON (6-diazo-5-oxo- I-norleucine) enhances nuclear/cytoplasmic maturation of porcine oocytes
}

\author{
Hae-Jun Yang ${ }^{1,2,6, *}$, Sanghoon Lee ${ }^{1, *}$, Bo-Woong Sim ${ }^{1,2, *}$, Pil-Soo Jeong ${ }^{1,2,5}$, Seon-A Choi ${ }^{1,2}$, \\ Young-Ho Park ${ }^{1,2,4}$, Bong-Seok Song ${ }^{1,2,4}$, Seung-Bin Yoon ${ }^{1,2,3,4}$, Philyong Kang ${ }^{1,2}$, \\ Kang-Jin Jeong ${ }^{1,2}$, Young-Hyun Kim ${ }^{2,4}$, Jae-Won Huh' ${ }^{2,4}$, Sang-Rae Lee ${ }^{2,4}$, Deog-Bon Koo ${ }^{5}$, \\ Young-Kug $\mathrm{Choo}^{6}$, Ji-Su Kim ${ }^{2,3}$ and Sun-Uk Kim ${ }^{1,2,4}$ \\ ${ }^{1}$ Futuristic Animal Resource \& Research Center, Korea Research Institute of Bioscience and Biotechnology, \\ Chungcheongbuk-do, Republic of Korea, ${ }^{2}$ National Primate Research Center, Korea Research Institute of Bioscience \\ and Biotechnology, Chungcheongbuk-do, Republic of Korea, ${ }^{3}$ Primate Resource Center, Korea Research Institute of \\ Bioscience and Biotechnology, Jeollabuk-do, Republic of Korea, ${ }^{4}$ Department of Functional Genomics, KRIBB \\ School of Bioscience, Korea University of Science and Technology (UST), Daejeon, Republic of Korea, ${ }^{5}$ Department \\ of Biotechnology, Daegu University, Gyeongsangbuk-do, Republic of Korea and ${ }^{6}$ Department of Biological Science, \\ College of National Sciences, Wonkwang University, Jeollabuk-do, Republic of Korea
}

Correspondence should be addressed to J-S Kim or S-U Kim; Email: kimjs@kribb.re.kr or sunuk@kribb.re.kr

*(H-J Yang, S Lee and B-W Sim contributed equally to this work)

\begin{abstract}
The developmental competence of in vitro-matured oocytes is still lower than that of the in vivo-matured oocytes due to precocious meiotic resumption and inappropriate cytoplasmic maturation. Although numerous efforts have been attempted to accomplish better in vitro maturation (IVM) condition, only limited progress has been achieved. Thus, a current study was conducted to examine the effects of 6-diazo-5-oxo-I-norleucine (DON, an inhibitor of hyaluronan synthesis) during the first half period of IVM on nuclear/ cytoplasmic maturation of porcine oocytes and subsequent embryonic development. Based on the observation of the nucleus pattern, metaphase II (MII) oocyte production rate in $1 \mu \mathrm{M}$ DON group was significantly higher than other groups at $44 \mathrm{~h}$ of IVM. The $1 \mu \mathrm{M}$ of DON was suggested to be optimal for porcine IVM and was therefore used for further investigation. Meiotic arrest effect of DON was maximal at $6 \mathrm{~h}$ of IVM, which was supported by the maintenance of significantly higher intra-oocyte cAMP level. In addition, increased pERK1/2 levels and clear rearrangement of cortical granules in membrane of MII oocytes matured with DON provided the evidence for balanced meiosis progression between nuclear and cytoplasmic maturation. Subsequently, DON significantly improved blastocyst formation rate, total cell numbers, and cellular survival in blastocysts after parthenogenetic activation, in vitro fertilization, and somatic cell nuclear transfer. Altogether, our results showed for the first time that $\mathbf{1} \mu \mathrm{M}$ DON can be used to increase the yield of developmentally competent MII oocytes by synchronizing nuclear/cytoplasmic maturation, and it subsequently improves embryo developmental competence.

Reproduction (2019) 158 543-554
\end{abstract}

\section{Introduction}

Pigs have been widely used in biomedical research, as a model for studying human diseases and xenotransplantation (Prather et al. 2003, Hall et al. 2013); this is due to the similarities between pigs and humans: their anatomy and physiology (Aigner et al. 2010). Several techniques for in vitro production (IVP) of preimplantation porcine embryos, including in vitro maturation (IVM), in vitro fertilization (IVF), in vitro culture (IVC), intracytoplasmic sperm injection (ICSI) and somatic cell nuclear transfer (SCNT), have been used (Betthauser et al. 2000, Nagashima et al. 2003) to produce pig models for specific purposes. However, the defects in early development of in vitro-produced porcine embryos are major obstacles for the generation of these pig models.

IVP of mammalian early embryos is still in need of further improvement by elucidating the developmental events or mechanisms for numerous developmental problems (Galli et al. 2012, Luo et al. 2012). Considering that the early development of porcine embryos is highly dependent on the quality of the oocytes (Krisher 2004), incomplete maturation of porcine oocytes via 
spontaneous meiotic resumption is one of the main reasons for improper development of in vitro-produced porcine embryos. When cumulus oocyte complexes (COCs) are removed from antral follicles using a disposable syringe or vacuum pump, oocytes undergo spontaneous meiotic resumption (Dieci et al. 2013). Therefore, to improve oocyte quality, a variety of reports suggest that transient meiotic arrest by preventing degradation of intra-oocyte CAMP is required to synchronize nuclear/cytoplasmic maturation and ultimately to improve the oocyte competence (Luciano et al. 1999, 2004, Ponderato et al. 2002). Temporary blockage of spontaneous meiotic resumption can be achieved through supplementing phosphodiesterases (PDEs) inhibitors (Mayes \& Sirard 2002, Lodde et al. 2013) or dibutyryl cAMP (Funahashi et al. 1997) into IVM media. In particular, various PDEs inhibitors such as milrinone (Grupen et al. 2006), cilostazole (Elahi et al. 2016), cilostamide, and rolipram (Laforest et al. 2005) have been used to improve porcine IVM, as they prevent the hydrolyze of cAMP and cGMP in oocytes.

Another way to retain high levels of cAMP in oocyte is to lower the level of hyaluronan by treating 6-diazo5-oxo-l-norleucine (DON; an inhibitor of hyaluronan synthesis). Hyaluronan is a linear glycosaminoglycan with a high-molecular-weight polymer and repeating disaccharides linked by 1-3 and $\alpha 1-4$ glycosidic bonds, which functions as a major component governing cumulus expansion (Yokoo et al. 2010). DON binds with and inactivates the aminotransferase that transfers an amino group from glutamine to fructose-6-phosphate, thus inhibiting the formation of glucosamine-6-phosphate (Bates et al. 1966). Glucosamine availability appears to be rate-limiting for the biosynthesis of hyaluronan (McCarty 1996) and inhibition of glucosamine synthesis is a molecular mechanism how DON inhibits hyaluronan synthesis. Since gap junctional communication between the oocyte and cumulus cells can be shut down by expanding cumulus cells under hormone stimulation (Chen et al. 1990), inhibition of cumulus expansion by DON treatment during initiation of maturation can keep the gap junction open, which leads to a continuous introduction of cumulus cell-origin cAMP into oocytes.

A previous study demonstrated that a majority of COCs cultured in IVM medium supplemented with DON were arrested at germinal vesicle (GV) stage, and there was tight association with cumulus cells (Yokoo et al. 2010). However, the effects of DON on cytoplasmic maturation of oocytes for subsequent embryo development and underlying mechanism(s) are largely unknown. In the current study, we investigated the effects of DON supplementation during initiation of IVM on quality of porcine oocytes through monitoring maturation and subsequent embryo development. To understand the relationship between these effects and meiotic arrest activity of DON, cAMP levels, ERK phosphorylation kinetics, cortical granule rearrangement, and expression of COCs-derived intrinsic factors (proteins and genes) regulating IVM were also investigated.

\section{Materials and methods}

\section{Chemicals}

All chemicals and reagents were purchased from SigmaAldrich Chemical Company, unless otherwise indicated.

\section{Oocyte recovery and in vitro maturation}

Porcine ovaries were collected from a local slaughterhouse and transported to the laboratory in $0.9 \%$ saline solution supplemented with $75 \mu \mathrm{g} / \mathrm{mL}$ potassium penicillin $\mathrm{G}$ and 50 $\mu \mathrm{g} / \mathrm{mL}$ streptomycin sulfate, which was maintained at $25-30^{\circ} \mathrm{C}$. COCs were separated from follicles (3-6 $\mathrm{mm}$ in diameter) by aspiration through an 18-gauge needle into a disposable $10 \mathrm{~mL}$ syringe. After washing COCs three times in TL-HEPES medium ( $1 \mathrm{mM} / \mathrm{mL}$ polyvinyl alcohol (PVA) in low-carbonate Tyrode albumin lactate pyruvate (TALP) medium), approximately 50 COCs were matured in a $500 \mu \mathrm{L}$ IVM medium in a fourwell multi-dish (Nunc, Roskilde, Denmark) at $38.5^{\circ} \mathrm{C}$ and under $5 \% \mathrm{CO}_{2}$ in air. The medium used for oocyte maturation was tissue culture medium 199 (TCM-199), supplemented with $10 \%$ porcine follicular fluid, $0.57 \mathrm{mM}$ cysteine, $25 \mu \mathrm{M}$ $\beta$-mercaptoethanol, $10 \mathrm{ng} / \mathrm{mL}$ epidermal growth factor (EGF), $10 \mathrm{IU} / \mathrm{mL}$ pregnant mare serum gonadotropin (PMSG), and 10 $\mathrm{IU} / \mathrm{mL}$ human chorionic gonadotropin (hCG). During the first half period of IVM (0-22 h), 0, 1, 5, and $10 \mu \mathrm{M}$ DON was supplemented into the IVM medium. After $22 \mathrm{~h}$ of culture, COCs were washed three times and then cultured in fresh hormone- and DON-free IVM medium for an additional 20-22 h.

\section{Assessment of nuclear maturation}

After culture for $0,6,22$, and $44 \mathrm{~h}$, COCs were denuded by gently pipetting in TL-HEPES medium containing $0.1 \%$ hyaluronidase to remove cumulus cells. Then, the denuded oocytes were washed three times in phosphate-buffered saline (PBS)-polyvinyl alcohol (PVA) (0.1\%) medium and fixed with $4 \%$ paraformaldehyde at $4{ }^{\circ} \mathrm{C}$ overnight. The oocytes were washed three times in PBS-PVA $(0.1 \%)$ and mounted on glass slides in a drop of DAPI (4'6-diaminoin-2-fenylindol). The meiotic stage was evaluated under ultraviolet (UV) light using an epifluorescence microscope (Olympus, Tokyo, Japan) at 200x magnification.

\section{Measurement of intra-oocytes cAMP}

After culture for $0,6,22$, and $44 \mathrm{~h}$, the COCs were denuded by gently pipetting in TL-HEPES medium containing $0.1 \%$ hyaluronidase and washed three times in PBS-PVA $(0.1 \%)$ medium. Forty of denuded oocytes were transferred into microtubes and stored at $-80^{\circ} \mathrm{C}$ until they were assayed. The cAMP levels in oocytes were measured using the cAMP assay kit (Cayman Chemical Co.), following the manufacturer's protocol. In brief, the $40 \mu \mathrm{L}$ of $5 \%$ trichloroacetic acid in 
water was added to the sample tube, and the sample was homogenized on ice using a Polytron-type homogenizer. After centrifugation at maximum speed for $10 \mathrm{~min}$, the precipitate was removed, and the supernatant was carefully transferred to a clean test tube. Trichloroacetic acid was extracted from the sample, using water-saturated ether. Five volumes of ether to one volume of supernatant was added and mixed for $10 \mathrm{~s}$, and the organic and aqueous phases were separated. Then, the top ether layer was carefully discarded. The residual ether from the aqueous layer was removed by heating the sample to $70^{\circ} \mathrm{C}$ for $5 \mathrm{~min}$. Each sample was transferred to a plate immediately, and the reagents were added, according to the manufacturer's protocol. Finally, the plate was read at a wavelength between 405 and $420 \mathrm{~nm}$, and the cAMP levels were calculated, in accordance with the instructions of the manufacturer.

\section{Western blot analysis}

Twenty oocytes of each group and cumulus cells separated from 20 oocytes of each group were washed twice with PBS-PVA and lysed in $20 \mu \mathrm{L}$ of lysis buffer $(20 \mathrm{mM}$ HEPES, $150 \mathrm{mM} \mathrm{NaCl}, 2 \mathrm{mM}$ EGTA, 2 mM EDTA, $20 \mathrm{mM}$ glycerol phosphate, $1 \%$ Triton $\mathrm{X}-100$, and $10 \%$ glycerol) containing a protease inhibitor cocktail for $2 \mathrm{~h}$, and subsequently boiled at $100^{\circ} \mathrm{C}$ for $10 \mathrm{~min}$. Proteins were separated by SDS-PAGE, transferred to nitrocellulose membranes (Millipore), and detected by immunoblotting. Membranes were blotted with primary antibodies against pERK (1:1000 dilution; \#4370L; Cell Signaling Technology), ERK (1:2000 dilution; \#9102S; Cell Signaling Technology), pAKT Ser473 (1:1000 dilution; \#4060L; Cell Signaling Technology), AKT (1:1000 dilution; \#9272s; Cell Signaling Technology), CCNB1 (1:1000 dilution; \#ADIKAM-CC195; Enzo Life Sciences, NY, USA), CDK1 (1:1000 dilution; \#sC-54; Santa Cruz Biotechnology), PRKAR1A (1:1000 dilution; \#ab230714; Abcam), PRKACA (1:1000 dilution; \#ab26322, Abcam), and GAPDH (1:2000 dilution; LF-PA0212; ABfrontier, Seoul, South Korea) at $4{ }^{\circ} \mathrm{C}$ overnight. The following day, membranes were washed three times with Tris-buffered saline with Tween-20 (TBST) buffer $(10 \mathrm{mM}$ Tris- $\mathrm{HCl}$ Tris- $\mathrm{HCl}$ (pH 7.5), $150 \mathrm{mM} \mathrm{NaCl}$ and $0.2 \%$ Tween-20) and incubated with horseradish peroxidase-conjugated goat anti-rabbit IgG or antimouse IgG at $4{ }^{\circ} \mathrm{C}$ overnight. The membranes were visualized using enhanced chemiluminescence detection reagent (ELPIS Biotech, Daejeon, South Korea), according to manufacturer's instructions. The band intensities were quantified using TINA20 software (Raytest GmbH, Straubenhardt, Germany).

\section{Staining of cortical granules}

Cumulus cell-free oocytes were fixed with $4 \%$ (w/v) paraformaldehyde in PBS for 30 min, washed three times with PBS containing $0.3 \%$ BSA (Fraction V) and $100 \mathrm{mM}$ glycine for 5 min each, and treated with $0.1 \%$ Triton X-100 in PBS for $5 \mathrm{~min}$. The oocytes were washed twice in PBS for $5 \mathrm{~min}$ each and incubated with FITC-labeled peanut agglutinin (100 $\mathrm{mg} / \mathrm{mL}$ ) in PBS for 30 min under dark condition for cortical granule staining. The oocytes were then washed three times in PBS containing $0.3 \%$ BSA and $0.01 \%$ Triton X-100. Finally, oocytes were mounted on clean glass slides and observed under a laser-scanning confocal fluorescent microscope (Zeiss LSM700).

\section{Real-time quantitative PCR (qPCR)}

Poly(A) mRNAs were extracted from 20 oocytes or embryos using the Dynabeads mRNA Direct Kit (Invitrogen), according to the manufacturer's protocol. Briefly, after thawing, samples were lysed in $300 \mu \mathrm{L}$ of lysis/binding buffer (Invitrogen) at room temperature for $10 \mathrm{~min}$, and $10 \mu \mathrm{L}$ of Dynabeads oligo(dT)25 was added to each sample. The beads were hybridized for 5 min and then separated from the binding buffer using a Dynal magnetic bar (Invitrogen). Bound poly (A) mRNAs and beads were washed with buffers A and B (Invitrogen) and separated by addition of $10 \mu \mathrm{L}$ of Tris buffer. The resulting poly (A) mRNAs were reverse transcribed in $20 \mu \mathrm{L}$ reactions containing oligo (dT) 20, 5× RT buffer (containing $25 \mathrm{mM} \mathrm{Mg}^{2+}+, 10 \mathrm{U}$ of the RNase inhibitor ReverTra Ace (Toyobo), and a $10 \mathrm{mM}$ mixture of dNTPs. Secondary RNA structure was denatured by incubating at $42^{\circ} \mathrm{C}$ for $20 \mathrm{~min}$ in order to facilitate cDNA production. The reaction was terminated by incubating at $99^{\circ} \mathrm{C}$ for $5 \mathrm{~min}$. The resulting CDNA was used as a template for PCR amplification. The following PCR conditions were used: $95^{\circ} \mathrm{C}$ for $30 \mathrm{~s}, 60^{\circ} \mathrm{C}$ for $30 \mathrm{~s}$, and $72^{\circ} \mathrm{C}$ for $30 \mathrm{~s}$, followed by extension at $72^{\circ} \mathrm{C}$ for $5 \mathrm{~min}$. The Mx3000P QPCR system (Agilent) and Brilliant III Ultra-fast SYBR Green QPCR Master Mix (Agilent) were used for qPCR. All oligonucleotide primer sequences are presented in Table 1. GAPDH was used as an internal standard for each group. Porcine primers were designed using Primer3 (http://bioinfo.ebc.ee/mprimer3).

\section{Parthenogenetic activation}

Cumulus cell-free MII oocyte were placed on a 1-mm gab wire chamber (CUY5000P1, NEPAGENE) overlaid with $10 \mu \mathrm{L}$ of 280 $\mathrm{mM}$ mannitol solution containing $0.1 \mathrm{mM} \mathrm{MgSO} \cdot 7 \mathrm{H}_{2} \mathrm{O}, 0.1$ $\mathrm{mM} \mathrm{CaCl} 2 \cdot 2 \mathrm{H}_{2} \mathrm{O}, 0.5 \mathrm{mM} \mathrm{HEPES}$ and $0.01 \%$ PVA, as described previously (Beebe et al. 2009). Oocytes were immediately activated with $1.1 \mathrm{kV} / \mathrm{cm}$ direct current (DC) for $50 \mu$ s using an electro cell fusion generator (LF101, NEPAGENE Co., China, Japan). The activated oocytes were placed into $40 \mu \mathrm{L}$ IVC medium supplemented with $5 \mu \mathrm{g} / \mathrm{mL}$ cytochalasin B (CB) and $2 \mathrm{mM}$ 6-dimethylaminopurine (6-DMAP) for $4 \mathrm{~h}$ at $38.5^{\circ} \mathrm{C}$. After $4 \mathrm{~h}$, oocytes were washed in IVC medium and transferred into $40 \mu \mathrm{L} \mathrm{IVC} \mathrm{medium} \mathrm{at} 38.5^{\circ} \mathrm{C}$ in an atmosphere of $5 \% \mathrm{CO}_{2}$ in air. Cleavage and blastocyst formation were evaluated on day 2 and day 6 , respectively.

\section{In vitro fertilization}

After IVM, oocytes were subjected to IVF as described previously (Kim et al. 2010). IVF was performed in modified Tris-buffered medium (mTBM), consisting of $113.1 \mathrm{mM} \mathrm{NaCl}$, $3 \mathrm{mM} \mathrm{KCl}, 7.5 \mathrm{mM} \mathrm{CaCl}{ }_{2} \cdot 2 \mathrm{H}_{2} \mathrm{O}, 20 \mathrm{mM}$ Tris (crystallized free base; Fisher Scientific, Fair Lawn, NJ, USA), 11 mM glucose, $5 \mathrm{mM}$ sodium pyruvate and no antibiotics. Fresh ejaculated semen was washed three times by centrifugation (100 $\mathbf{g}$ for $3 \mathrm{~min}$ at room temperature) in Dulbecco's PBS (DPBS; Gibco-BRL) supplemented with $1 \mathrm{mg} / \mathrm{mL}$ BSA, $100 \mu \mathrm{g} / \mathrm{mL}$ 
Table 1 PCR sequences used for real-time PCR.

\begin{tabular}{|c|c|c|c|c|}
\hline \multirow[b]{2}{*}{ Genes } & \multicolumn{2}{|c|}{ Primer sequences } & \multirow[b]{2}{*}{ Accession number } & \multirow[b]{2}{*}{ Product size $(b p)$} \\
\hline & Forward & Reverse & & \\
\hline CCNB1 & AAGATGGAGGGGATCCAAAC & TGGCTCTCATGTTTCCAGTG & NM_001170768.1 & 135 \\
\hline$C D K 1$ & CGCGGGATAATAAGCTGGGA & CATGGCTACCACTTGACСТGT & NM_001159304.2 & 139 \\
\hline HAS1 & СTCTGGACTCTTGGGTCAGC & CAGACCTAGGGGACCACTGA & NM_001136212.1 & 119 \\
\hline HAS2 & TTAGTGGACCTCTGGGGATG & AGACTCAGCACTCGGTTCGT & NM_214053.1 & 133 \\
\hline PRKAR1A & CGTTGGAACCAGTCCAGTTT & ATCAGAAGGCCCCAATCTTC & NM_214026.1 & 158 \\
\hline$P R K A C A$ & СССTGGGGGTTCTCATCTAT & ATGGCAATCCAGTCAGTCGT & XM_003354103.2 & 247 \\
\hline
\end{tabular}

penicillin $\mathrm{G}$ and $75 \mu \mathrm{g} / \mathrm{mL}$ streptomycin sulfate. After washing, the sperm pellet was resuspended in mTBM. The oocytes were washed three times in mTBM with $2.5 \mathrm{mM}$ caffeine sodium benzoate and $4 \mathrm{mg} / \mathrm{mL}$ BSA (fatty acid free) and placed into 48 $\mu \mathrm{L}$ mTMB under mineral oil. Diluted spermatozoa $(2 \mu \mathrm{L})$ were added to $48 \mu \mathrm{L}$ mTBM containing 15-25 oocytes, giving a final concentration of $1.5 \times 10^{5}$ spermatozoa $/ \mathrm{mL}$. The oocytes were co-incubated with the spermatozoa for $6 \mathrm{~h}$ at $38.5^{\circ} \mathrm{C}$ in an atmosphere of $5 \% \mathrm{CO}_{2}$ in air. After $6 \mathrm{~h}$, the oocytes were denuded by gently pipetting to remove spermatozoa, and transferred to IVC medium (PZM-3 containing 0.4\% BSA). To count pronuclei, fertilized embryos at $10 \mathrm{~h}$ after insemination were washed three times with PBS-PVA $(0.1 \%)$ and fixed with $4 \%$ paraformaldehyde overnight at $4{ }^{\circ} \mathrm{C}$. Then, they were washed three times in PVA-PBS $(0.1 \%)$ and mounted on glass slides in a drop of DAPI. Pronuclei were observed under UV light using an epifluorescence microscope at 200x magnification. The other embryos were cultured in $40 \mu \mathrm{L}$ drops of IVC medium at $38.5^{\circ} \mathrm{C}$ in an atmosphere of $5 \% \mathrm{CO}_{2}$ in air. The number of embryos cleaved and developed to blastocysts stage was scored at 2 and 6 days of IVC, respectively.

\section{Somatic cell nuclear transfer}

After IVM, matured oocytes with a visible first polar body were selected for SCNT. Cumulus cell-free oocytes in PB1 (DPBS supplemented with $4 \mathrm{mg} / \mathrm{mL}$ BSA, $75 \mu \mathrm{g} / \mathrm{mL}$ penicillin G, $50 \mu \mathrm{g} / \mathrm{mL}$ streptomycin sulfate) containing $7.5 \mu \mathrm{g} / \mathrm{mL}$ $\mathrm{CB}$ were enucleated by sharp pipette under an automated inverted microscope (DMI 4000B, LEICA) equipped with a micromanipulator (NT-88-V3, NIKON NARISHIGE, Japan). Porcine kidney cells were selected as donor cell to construct SCNT embryos, as they exhibited a higher proliferation rate and blastocyst formation rate after SCNT compared to porcine fetal or ear fibroblasts (Richter et al. 2012). Porcine kidney cells (at passages 4-6) that were round, had a 15-20 $\mu \mathrm{m}$ diameter, and good refractivity were selected and placed into the perivitelline space through the near slit in the zona pellucida that had been made for enucleation. For electrical fusion, a single cell-oocyte couplet was sandwiched between two parallel electrodes (CUY 5100-100, NEPA GENE) approximately $100 \mu \mathrm{m}$ apart attached to micromanipulator. The contact surface between the cytoplasm and the donor cell was parallel to the electrodes, and fused by one direct current pulse of $0.23 \mathrm{kV} / \mathrm{cm}$ for $50-\mu$ s using an Electro Cell Fusion generator in fusion medium consisting of $280 \mathrm{mM}$ mannitol containing $0.1 \mathrm{mM} \mathrm{MgSO} \cdot 7 \mathrm{H}_{2} \mathrm{O}, 0.01 \%$ PVA (Beebe et al. 2009), and incubated at $38.5^{\circ} \mathrm{C}$ in $5 \% \mathrm{CO}_{2}$ in air. After $2 \mathrm{~h}$, oocyte-cell couplets that were found to be completely fused under an automated inverted microscope were selected, then transferred to a $1 \mathrm{~mm}$ gap wire chamber overlaid with $10 \mu \mathrm{L}$ $280 \mathrm{mM}$ mannitol solution containing $0.1 \mathrm{mM} \mathrm{MgSO} \cdot 7 \mathrm{H}_{2} \mathrm{O}$, $0.1 \mathrm{mM} \mathrm{CaCl} 2 \cdot 2 \mathrm{H}_{2} \mathrm{O}, 0.5 \mathrm{mM} \mathrm{HEPES}$, and $0.01 \%$ PVA and activated with $110 \mathrm{~V}$ DC for $50 \mu \mathrm{sec}$ using an electro cell fusion generator. The electro-activated oocytes were transferred into the chemically assisted activation medium supplemented with $50 \mathrm{nM}$ trichostatin A (TSA) for $4 \mathrm{~h}$ at $38.5^{\circ} \mathrm{C}$ in $5 \% \mathrm{CO}_{2}$ in air. After $4 \mathrm{~h}$, activated embryos were transferred in IVC medium supplemented with $50 \mathrm{nM}$ TSA and cultured until 20 h. After 20 h, oocytes were washed in IVC medium without TSA and transferred to IVC medium without TSA at $38.5^{\circ} \mathrm{C}$ in $5 \% \mathrm{CO}_{2}$ in air. Cleavage and blastocyst formation were evaluated on day 2 and day 6 , respectively.

\section{Differential staining}

After 6 days in culture, blastocyst formation was observed and the number of inner cell mass (ICM) and trophectoderm (TE) was determined by differential staining, as described previously (Kim et al. 2010). The zona pellucida of the blastocysts was removed by 1 min incubation in $0.5 \%$ pronase solution. After washed in PBS-PVA $(0.1 \%)$, the zona pellucidafree blastocysts were exposed to a 1:5 dilution of rabbit antipig whole serum for $1 \mathrm{~h}$. Then, they were washed three times for 5 min each time in TL-HEPES and placed in a 1:10 dilution of guinea-pig complement containing $10 \mu \mathrm{g} / \mathrm{mL}$ propidium iodide (PI) and $10 \mu \mathrm{g} / \mathrm{mL}$ Hoechst 33342 (bisbenzimide) for $1 \mathrm{~h}$. After a brief wash, the zona pellucida-free blastocysts were examined under UV light using an epifluorescence microscope (Olympus).

\section{TUNEL assay}

To apoptotic cells in the blastocysts, the terminal deoxynucleotidyl transferase-mediated dUTP-digoxygenin nick end-labeling (TUNEL) assay was performed using an In Situ Cell Death Detection Kit (Roche, Basel, Swiss). Blastocysts were harvested at day 6, washed three times in DPBS containing $1 \mathrm{mg} / \mathrm{mL}$ PVA, and fixed in $4 \%$ paraformaldehyde overnight at $4{ }^{\circ} \mathrm{C}$. Fixed blastocysts were permeabilized in DPBS containing 0.5\% (v/v) Triton X-100 at room temperature for $30 \mathrm{~min}$. Nonspecific binding sites were blocked by incubation with PBS containing $10 \mathrm{mg} / \mathrm{mL}$ BSA for $1 \mathrm{~h}$. Subsequently, blastocysts were washed three times in PBS-PVA and stained with fluorescein conjugated dUTP and terminal deoxynucleotidyl transferase for $1 \mathrm{~h}$ at $38.5^{\circ} \mathrm{C}$. As a positive control for the TUNEL reaction, a group of blastocysts was incubated in $1000 \mathrm{IU} / \mathrm{mL}$ deoxyribonuclease at $38.5^{\circ} \mathrm{C}$ 
for $10 \mathrm{~min}$, followed by TUNEL staining. Another group of blastocysts was incubated in fluoresceind UTP in the absence of terminal deoxynucleotidyl transferase as a negative control. Subsequently, the blastocysts were washed three times in PBSPVA and mounted on slides with mounting solution containing $1.5 \mu \mathrm{g} / \mathrm{mL}$ DAPI. DAPI-labeled or TUNEL positive nuclei were observed with a fluorescence microscope.

\section{Confocal microscopy of hyaluronan content}

After culture for $0,6,22$, and $44 \mathrm{~h}$, the COCs were fixed in $4 \%$ paraformaldehyde. The fixed COCs were washed three times in PBS-PVA and then incubated in blocking solution $(10 \%$ normal goat serum in PBS-PVA) for $1 \mathrm{~h}$ at room temperature. The COCs were stained with biotinylated hyaluronan binding protein (1:100; \#AMS.HKD-BC41, Amsbio, Abingdon, UK) in blocking solution $4{ }^{\circ} \mathrm{C}$ for $4 \mathrm{~h}$. Fluorophore conjugated Streptavidin (2 ng/ml; \#016-540-084, Jackson immuno research laboratories, PA, USA) was used as a secondary conjugate in blocking solution at room temperature for $2 \mathrm{~h}$. After the final three times wash with PBS-PVA, the COCs were mounted with Vectashield containing DAPI (Vector Laboratories, CA, USA) on clean glass slides and observed under a laser-scanning confocal fluorescent microscope (Zeiss LSM700, Germany).

\section{Measurement of cumulus expansion}

After $0,6,22$, and 44 h of IVM, morphology of COCs was observed using inverted microscope (LEICA, Germany). Cumulus area from COCs was measured using Image J software (National Institutes of Health, Bethesda, MD, USA) and normalized to control group.

\section{Confocal microscopy of active mitochondria}

To assess the distribution of active mitochondria, oocytes were stained after $44 \mathrm{~h}$ of IVM. A stock solution of the dye at a concentration of $1 \mathrm{mM}$ was prepared in dimethyl sulfoxide and stored at $-20^{\circ} \mathrm{C}$. Oocytes were stained with $0.5 \mu \mathrm{M}$ MitoTracker Deep Red FM (M22426, Invitrogen) in IVM medium for $30 \mathrm{~min}$ at $39^{\circ} \mathrm{C}$ in $5 \% \mathrm{CO}_{2}$ in air. Labeled oocytes were then washed in PBS-PVA, three times for 15 min each. After washing, samples were fixed in $4 \%$ paraformaldehyde for $2 \mathrm{~h}$ at room temperature. After fixed samples were washed three times for 15 min each in PBS-PVA, oocytes were mounted on slide glasses in Vectashield containing DAPI (Vector Laboratories) and observed under a laser-scanning confocal fluorescent microscope (Zeiss LSM700, Germany).

\section{Confocal microscopy of actin filaments}

To assess the distribution of the membrane actin, oocytes were stained after $44 \mathrm{~h}$ of IVM. After three washes with PBS-PVA, oocytes were fixed in $4 \%$ paraformaldehyde overnight at $4{ }^{\circ} \mathrm{C}$. The fixed oocytes were washed three times in PBS-PVA and then incubated in blocking solution (PBS-PVA supplemented with $2 \% \mathrm{BSA}$ ) for $1 \mathrm{~h}$ at room temperature. Then, oocytes were stained with $10 \mu \mathrm{g} / \mathrm{ml}$ phalloidin-tetramethylrhodamine B isothiocyanate (Phalloidin-TRITC, P1951) for $2 \mathrm{~h}$ at room temperature. After the final three times wash with PBS-PVA, oocytes were mounted with Vectashield containing DAPI (Vector Laboratories) on clean glass slides and observed under a laser-scanning confocal fluorescent microscope (Zeiss LSM700).

\section{Statistical analysis}

All experiments were repeated at least three times. Data are presented as the means \pm SEM. The results were compared by one-way ANOVA, followed by Tukey's multiple range test or Student's $t$-test using SigmaStat software (SPSS, Inc.). $P$ values less than 0.05 were considered to be statistically significant.

\section{Results}

\section{Effect of various concentrations of DON supplementation during first half period of IVM on nuclear maturation}

To examine the effect of transient meiotic arrest activity of DON on the nuclear maturation of porcine oocytes during first half period of IVM, COCs were cultured in $0,1,5$ and $10 \mu \mathrm{M}$ DON for $22 \mathrm{~h}$ and subjected to nucleus staining analysis using DAPI for determination of meiotic developmental stages. Compared to control, administration of DON led to a significant increase of proportion of GV stage oocytes in a dose-dependent manner $(10.1 \pm 1.5$ vs $24.2 \pm 1.5, \quad 30.2 \pm 3.3$ and $46.4 \pm 4.5 \%$, respectively, $P<0.05)$ and highest $(P<0.05)$ proportion was found in $10 \mu \mathrm{M}$ DON treatment group. In terms of germinal vesicle breakdown (GVBD) stage, 1 and $5 \mu \mathrm{M}$ DON showed significant higher GVBD

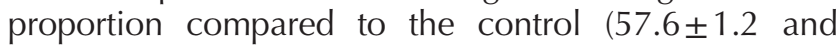
$58.8 \pm 3.4$ vs $45.9 \pm 1.8 \%, P<0.05)$. In addition, the proportion of metaphases I (MI) stage was significantly decreased in DON treatment groups compared to control $(18.2 \pm 1.2,10.9 \pm 1.0,3.3 \pm 1.3$ vs $44.0 \pm 2.4 \%, P<0.05$ Fig. $1 \mathrm{~B})$. At the other half period of IVM culture without DON supplementation, metaphase II (MII) stage was significantly increased in only $1 \mu \mathrm{M}$ group compared to control $(83.7 \pm 0.8$ vs $75.5 \pm 1.1 \%, P<0.05$; Fig. $1 \mathrm{C})$. Based on nuclear maturation rate at the end of IVM, $1 \mu \mathrm{M}$ DON was suggested to be optimal for porcine IVM. Then, to clarify meiotic arrest activity of DON, meiosis progression was assessed after 3, 6, and 9 h of IVM. No differences in GV stage arrest were found after $3 \mathrm{~h}$ and $9 \mathrm{~h}$ of IVM $(82.5 \pm 2.5$ vs $80.0 \pm 2.3 \%$ and $54.4 \pm 2.2$ vs $50.0 \pm 2.3 \%$, respectively; Fig. 1D). However, at 6 h of IVM, oocytes matured with $1 \mu \mathrm{M}$ DON showed a significant increase in proportion of GV stage compared to the control $(75.6 \pm 3.2$ vs $63.8 \pm 2.3 \%, P<0.05$; Fig. 1D). To investigate how DON exerted meiotic arrest activity, the concentration of cAMP was assessed after 6, 22 , and 44 h of IVM. At 6 h of IVM, the concentration of CAMP in $1 \mu \mathrm{M}$ DON group was significantly higher than control group $(1.27 \pm 0.05$ pmol/oocyte vs $0.53 \pm 0.05$ pmol/oocyte, $P<0.05$; Fig. 1E). Additionally, the effects 


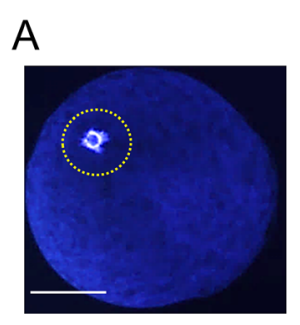

GV

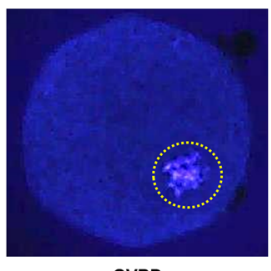

GVBD

C

B
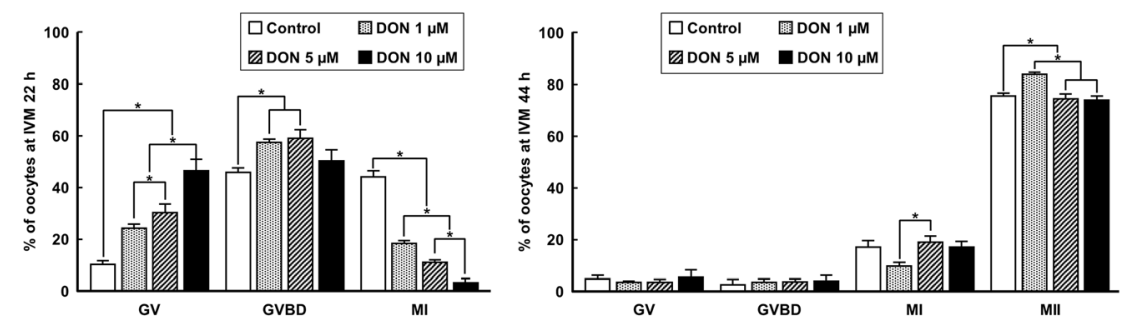

$\mathrm{D}$
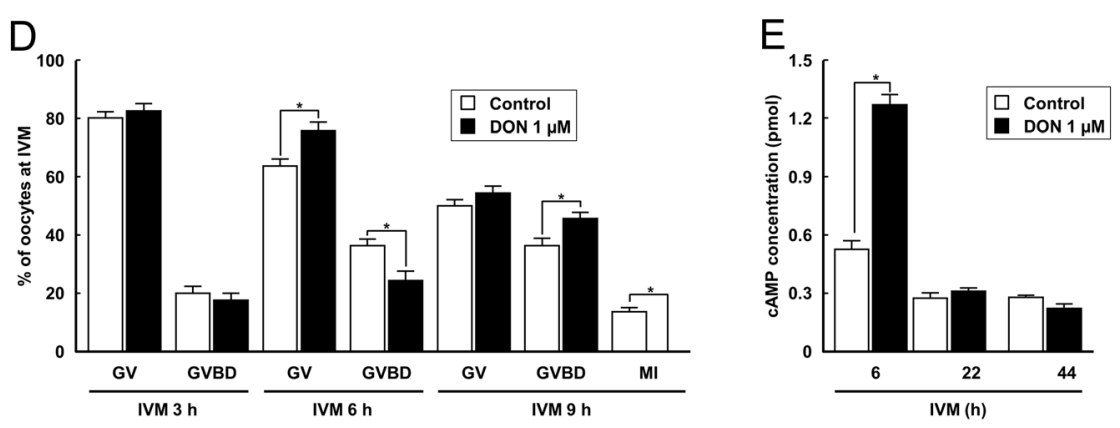

Figure 1 Effect of DON supplementation during the first half period of IVM on the meiotic progression of porcine oocytes. (A) Representative images for determination of oocyte nucleus pattern after DAPI staining (dotted circle). GV, germinal vesicle; GVBD, germinal vesicle breakdown; MI, metaphase I; MII, Metaphase II. Bar $=50 \mu \mathrm{m}$. (B) Effect of various concentrations of DON

supplementation during the first half period of IVM on oocyte nucleus pattern after $22 \mathrm{~h}$ of IVM. In total, 402 oocytes were used. (C) Effect of various concentrations of DON supplementation during the first half period of IVM on oocyte nucleus pattern after $44 \mathrm{~h}$ of IVM. In total, 433 oocytes were used. (D) Effect of $1 \mu \mathrm{M}$ DON supplementation during first half period of IVM on oocyte nucleus pattern after 3, 6 and $9 \mathrm{~h}$ of IVM. In total, 960 oocytes were used. (E) Effect of $1 \mu \mathrm{M}$ DON supplementation during first half period of IVM on intra-oocyte CAMP concentration after 6, 22 and 44 h of IVM. In total, 1200 oocytes were used. The data are from at least three independent experiments and the values represent the means \pm S.E.M. $\left({ }^{*} P<0.05\right)$. of DON supplementation during first half period of IVM on hyaluronan contents and area of cumulus expansion were investigated. Hyaluronan contents were decreased in $1 \mu \mathrm{M}$ DON treatment group compared to control at 6, 22 and $44 \mathrm{~h}$ of IVM (Supplementary Fig. 1A, see section on supplementary materials given at the end of this article). In terms of area of cumulus expansion (Supplementary Fig. 1B and C), there was no significant difference in area of cumulus expansion between control and DON treatment groups at 0 and $6 \mathrm{~h}$ of IVM. However, at 22 and $44 \mathrm{~h}$ of IVM, COCs of DON treatment group showed significantly $(P<0.05)$ decreased area of cumulus expansion (Supplementary Fig. 1C).

\section{Effect of DON supplementation during first half period of IVM on cytoplasmic maturation}

The effect of DON supplementation during first half period of IVM on pAKT and pERK1/2 expression level was investigated. The pAKT protein level was significantly $(P<0.05)$ increased in $1 \mu \mathrm{M} \mathrm{DON}$ treatment group compared to control at $6 \mathrm{~h}$ of IVM (Fig. $2 \mathrm{~A}$ and $\mathrm{B})$. However, there was no significant difference at $22 \mathrm{~h}$ and $44 \mathrm{~h}$ of IVM. In addition, protein expression level of pERK $1 / 2$ was significantly $(P<0.05)$ increased by 1 $\mu \mathrm{M}$ DON supplementation at $44 \mathrm{~h}$ of IVM. However, expression level of pERK1 at 6 and $22 \mathrm{~h}$ of IVM and

Reproduction (2019) 158 543-554
pERK2 at $22 \mathrm{~h}$ of IVM was significantly $(P<0.05)$ decreased (Fig. 2A and B). To investigate rearrangement of cortical granule, MII oocytes matured with or without $1 \mu \mathrm{M}$ DON were labeled with FITC-labelled peanut agglutinin. MII oocytes treated with $1 \mu \mathrm{M}$ DON showed a more sharp and tight form of cortical granule staining and significant decreased left and right lectin thicknesses $(5.5 \pm 0.3$ vs $11.4 \pm 1.1$ and $5.1 \pm 0.3$ vs $11.1 \pm 1.6 \mu \mathrm{M}$, respectively, $P<0.05$; Fig. $2 \mathrm{C}$ and $\mathrm{D})$. Furthermore, distributions of mitochondria and actin filaments in MII oocytes matured with or without $1 \mu \mathrm{M}$ DON were investigated. DON treatment group showed significantly $(P<0.05)$ higher diffuse mitochondrial distribution and lower semi-peripheral mitochondrial distribution compared to the control group (Supplementary Fig. 2A and B). However, in actin status, there was no significant difference in normal and abnormal distribution between control and DON treatment groups (Supplementary Fig. $2 \mathrm{C}$ and D). Then, expression levels of transcripts related to maturation promoting factor (MPF) and protein kinase $\mathrm{A}$ (PKA) in oocytes and cumulus expansion in cumulus cells were investigated at $6 \mathrm{~h}$ of IVM. MPFrelated genes (CCNB1 and CDK1) in oocytes and cumulus expansion-related genes (HAS1 and HAS2) were significantly $(P<0.05)$ decreased in DON-treated oocytes and cumulus cells at $6 \mathrm{~h}$ of IVM, respectively (Fig. 2E). In terms of PKA transcripts expression level, 
A
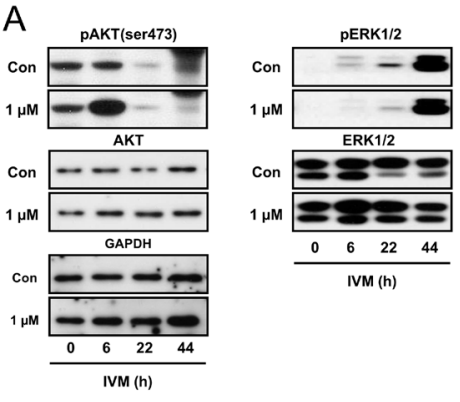

B

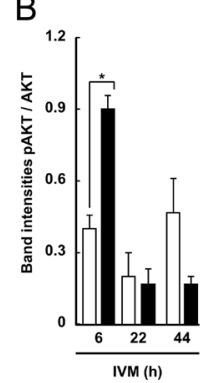

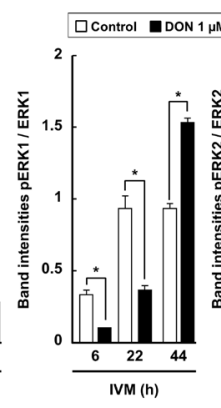

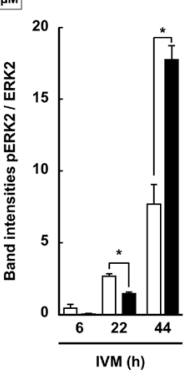

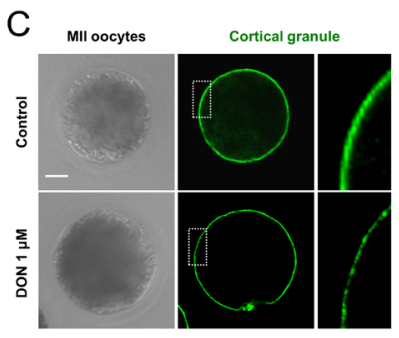
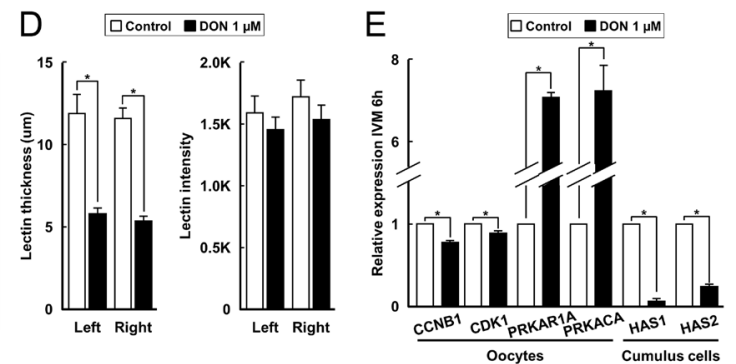

Figure 2 Effect of DON supplementation during the first half period of IVM on cytoplasmic maturation of porcine oocytes. (A) Western blot analysis of pAKT, AKT, pERK1/2 and ERK $1 / 2$ in oocytes matured in the presence or absence of $1 \mu \mathrm{M} \mathrm{DON}$ at $0,6,22$ and $44 \mathrm{~h}$ of IVM. (B) The band intensities of pAKT against AKT and pERK1/2 against ERK were densitometrically analyzed. In total, 840 oocytes were used. (C) Representative images of staining of cortical granules in MII oocytes matured in the presence or absence of $1 \mu \mathrm{M}$ DON at $44 \mathrm{~h}$ of IVM. Bar $=50 \mu \mathrm{m}$. (D) Measurement of a thickness ( $D$, left) and intensity ( $D$, right) of peanut agglutinin signals in MII oocytes matured in the presence or absence of $1 \mu \mathrm{M}$ DON at $44 \mathrm{~h}$ of IVM. In total, 44 oocytes were used. (E) The qPCR analysis for measurement of maturation promoting factor (MPF)-, protein kinase $\mathrm{A}$ (PKA)- and cumulus expansion-associated transcripts levels in oocytes or cumulus cells matured in the presence or absence of $1 \mu \mathrm{M}$ DON at $6 \mathrm{~h}$ of IVM. In total, 120 oocytes were used. The data are from at least three independent experiments and the values represent the means \pm S.E.M. $\left({ }^{*} P<0.05\right)$.
$1 \mu \mathrm{M}$ DON supplementation significantly $(P<0.05)$ increased PRKAR1A and PRKACA expression levels in oocytes (Fig. 2E). Additionally, the effect of DON supplementation during first half period of IVM on the protein expression levels of CCNB1, CDK1, PRKAR1A and PRKACA in oocytes and pERK1/2 in cumulus cells at 6, 22 and 44 h of IVM were investigated (Supplementary Fig. 3). As shown in Supplementary Fig. 3A and B, DON supplementation during first half period of IVM significantly $(P<0.05)$ increased the protein expression of CCNB1, CDK1, PRKAR1A and PRKACA in oocytes at 6, 22 and $44 \mathrm{~h}$ of IVM compared to the control. There was no significant difference in pERK1/2 level between control and DON treatment groups in cumulus cells at 6, 22 and 44 h of IVM (Supplementary Fig. 3C and D).

\section{Effect of DON-assisted IVM on subsequent embryo development after PA and IVF}

The $1 \mu \mathrm{M}$ DON-treated group was selected as optimal condition for IVM, because MII oocyte rate was significantly $(P<0.05)$ increased at the end of IVM. We investigated subsequent embryo development after PA and IVF as an indirect cytoplasmic maturation parameter, including blastocyst formation rate, number of ICM/TE cells and monospermy. After PA, $1 \mu \mathrm{M}$ DON significantly $(P<0.05)$ increased the rate of blastocyst formation $(51.3 \pm 3.2$ vs $37.5 \pm 3.6 \%$, Fig. $3 \mathrm{~A}$ and B) and total cell number $(32.7 \pm 0.1$ vs $28.1 \pm 0.4)$ including ICM/TE cell number $(10.0 \pm 0.2$ vs $8.3 \pm 0.1$ and $22.7 \pm 0.3$ vs $19.7 \pm 0.5, P<0.05$; Fig. $3 C$ ) and decreased the number and percentage of apoptotic cells in blastocysts compared to the control $(2.2 \pm 0.1 \mathrm{vs}$
$3.3 \pm 0.1$ and $6.2 \pm 0.4$ vs $11.3 \pm 0.5 \%, P<0.05$; Fig. $3 \mathrm{D})$. After IVF, DON at $1 \mu \mathrm{M}$ significantly $(P<0.05)$ increased the rate of monospermy $(51.8 \pm 0.6$ vs $34.1 \pm 2.7 \%$, Fig. $4 \mathrm{~B})$ and decreased the rate of polyspermy post IVF 10 h $(27.8 \pm 3.0$ vs $56.5 \pm 1.9 \%$, Fig. 4B). Furthermore, the rate of blastocyst formation $(39.3 \pm 0.9$ vs $29.3 \pm 1.5 \%$, Fig. 4D) and total cell number $(39.0 \pm 0.6$ vs $31.6 \pm 1.2)$ including ICM/TE cell number $(9.3 \pm 0.3$ vs $7.9 \pm 0.3$ and $29.3 \pm 0.8$ vs $23.8 \pm 0.8$, Fig. $4 \mathrm{E}$ ) were significantly $(P<0.05)$ increased and the percentage of apoptotic cell in blastocysts was significantly $(P<0.05)$ decreased in $1 \mu \mathrm{M}$ DON treatment group $(8.3 \pm 0.1$ vs $5.7 \pm 0.1 \%$, Fig. 4F).

\section{Effect of DON-assisted IVM on subsequent embryo development after SCNT}

Finally, we examined whether DON-assisted IVM could improve preimplantation embryo development of SCNT embryos. After SCNT, the rate of cell-oocyte fusion was significantly increased in $1 \mu \mathrm{M}$ DON treatment group compared to control $(79.7 \pm 0.9$ vs $72.5 \pm 1.0 \%$, $P<0.05$; Fig. 5B). Moreover, the blastocysts formation rate was significantly increased in $1 \mu \mathrm{M}$ DON-treated group compared to control $(41.8 \pm 2.1$ vs $30.1 \pm 1.1 \%$, $P<0.05$; Fig. $5 \mathrm{~A}$ and B). The quality of blastocysts was assessed by counting the total cell number including ICM/TE cell number and apoptotic cell. Supplementation of $1 \mu \mathrm{M}$ DON significantly increased the cell number of blastocysts $(40.7 \pm 0.7$ vs $28.3 \pm 1.1 \%, P<0.05$; Fig. 5C) with a significantly increased number of ICM cell $(8.0 \pm 0.4$ vs $6.4 \pm 0.3 \%, P<0.05$; Fig. $5 \mathrm{C})$ and TE cell of blastocyst ( $32.7 \pm 1.0$ vs $21.9 \pm 0.9 \%, P<0.05$; Fig. $5 \mathrm{C})$. 
A

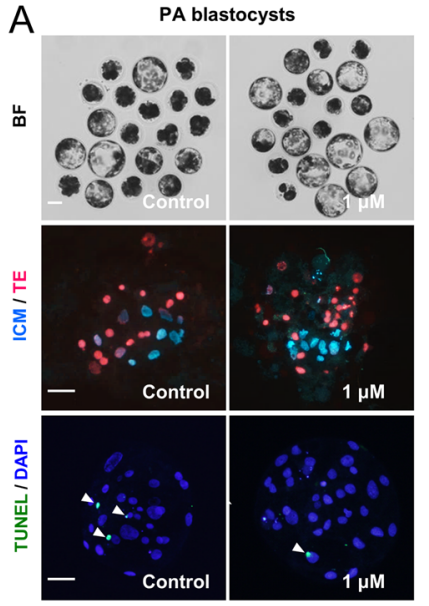

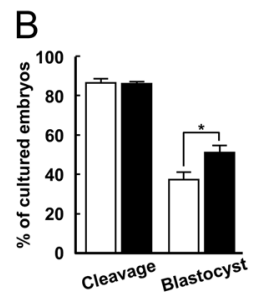
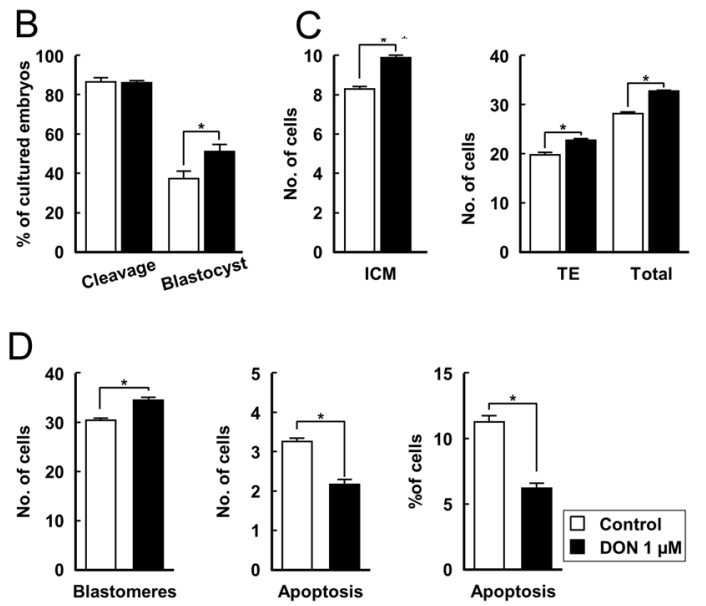

Figure 3 Effect of DON-assisted IVM on the subsequent development of parthenogenetic embryos. (A, top) Representative images of blastocysts developed from oocytes matured in the presence or absence of $1 \mu \mathrm{M}$ DON. Bar $=100 \mu \mathrm{m}$. (A, middle) Differential staining of ICM and TE cells in blastocysts in the indicated groups. The nuclei of ICM and TE cells were stained with Hoechst (blue) and PI (red) dye, respectively. Bar $=50 \mu \mathrm{m}$. (A, bottom) Apoptosis detection analysis using blastocysts of the indicated groups. Merged images between TUNEL (green, white arrow) and DAPI (blue) signals are shown. Bar $=50$ $\mu \mathrm{m}$. (B) The rate of cleavage and blastocyst formation. In total, 210 embryos were used. (C) Quantification of total cell numbers in the blastocysts including ICM and TE cells of the indicated groups. In total, 63 blastocysts were used. (D) Quantification of the numbers and proportions of apoptotic cells in the indicated groups. In total, 63 blastocysts were used. The data are from at least three independent experiments and the values represent the means \pm S.E.M. $(* P<0.05)$.

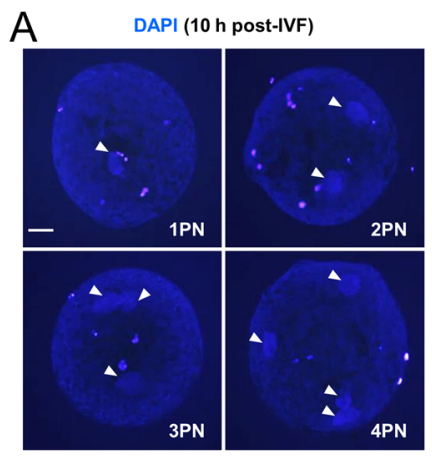

C
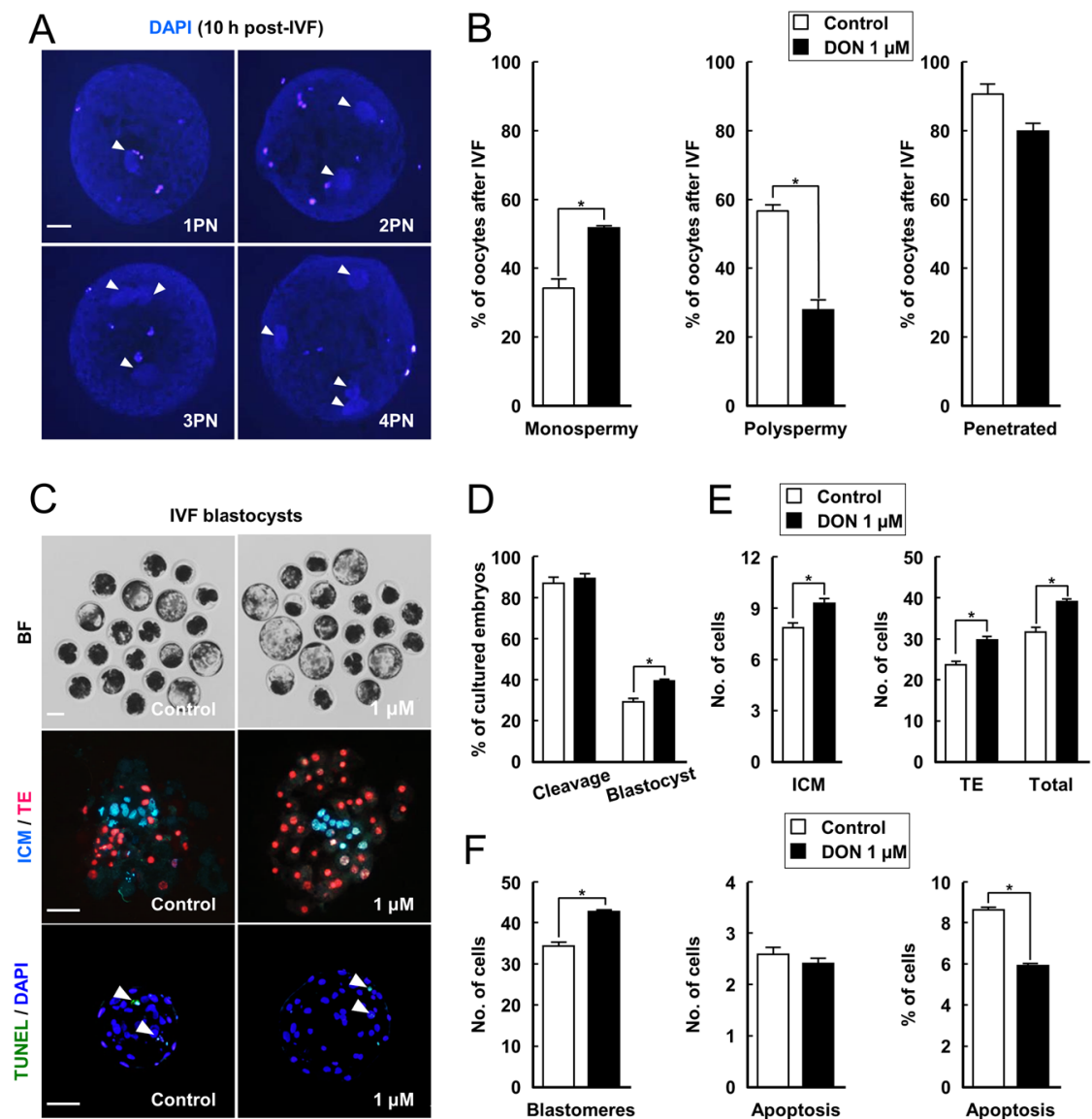

$\mathrm{F}$
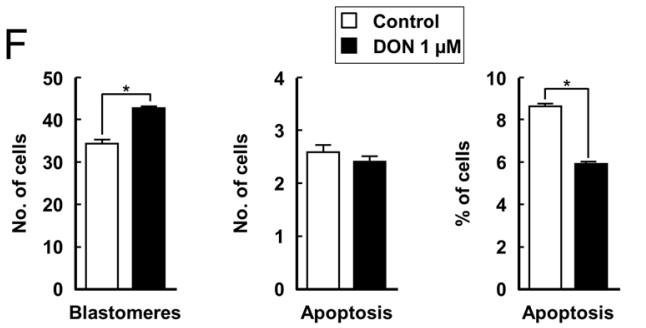

Figure 4 Effect of DON-assisted IVM on the subsequent development of in vitro-fertilized embryos. (A) Representative images of various pronuclear formation (white arrow). Bar $=50$ $\mu \mathrm{m}$. (B) The rate of monospermy, polyspermy and fertilization after IVF $10 \mathrm{~h}$. In total, 191 embryos were used. (C, top) Representative images of blastocysts developed from oocytes matured in the presence or absence of $1 \mu \mathrm{M}$ DON. Bar $=100 \mu \mathrm{m}$. (C, middle) Differential staining of ICM and TE cells in blastocysts in the indicated groups. The nuclei of ICM and TE cells were stained with Hoechst (blue) and $\mathrm{PI}$ (red) dye, respectively. Bar $=50 \mu \mathrm{m}$. (C, bottom) Apoptosis detection analysis using blastocysts of the indicated groups. Merged images between TUNEL (green, white arrow) and DAPI (blue) signals are shown. Bar $=50$ $\mu \mathrm{m}$. (D) The rate of cleavage and blastocyst formation. In total, 191 embryos were used. (E) Quantification of total cell numbers in the blastocysts including ICM and TE cells of the indicated groups. In total, 50 blastocysts were used. (F) Quantification of the numbers and proportions of apoptotic cells in the indicated groups. In total, 109 blastocysts were used. The data are from at least three independent experiments and the values represent the means \pm S.E.M. $(* P<0.05)$. 

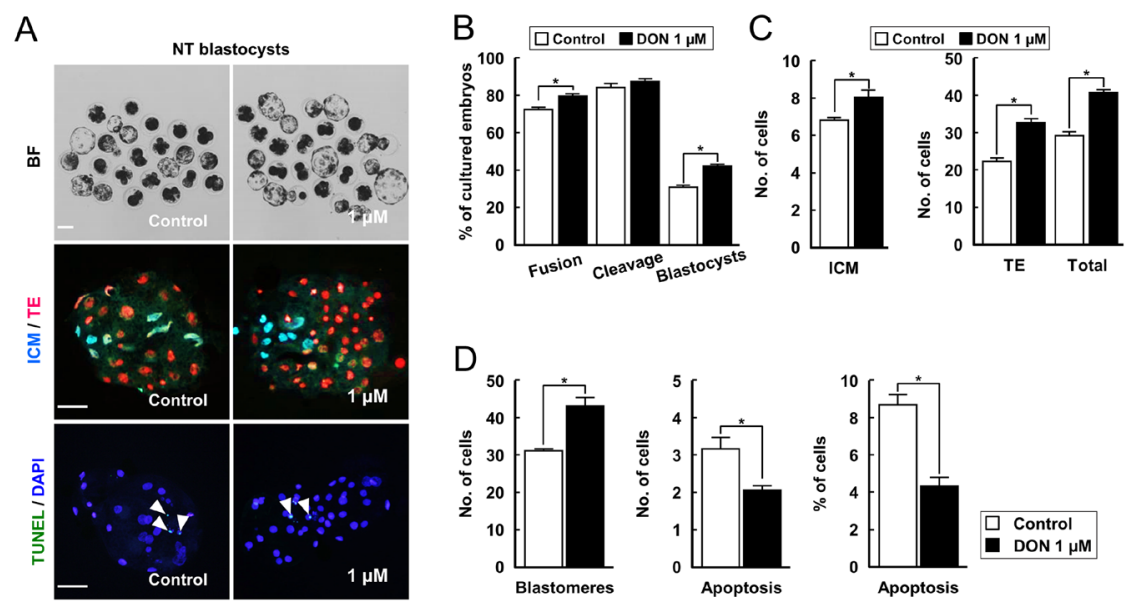

Figure 5 Effect of DON-assisted IVM on the subsequent development of somatic cell nuclear transferred embryos. (A, top) Representative images of blastocysts developed from oocytes matured in the presence or absence of $1 \mu \mathrm{M} \mathrm{DON}$. Bar $=100$ $\mu \mathrm{m}$. (A, middle) Differential staining of ICM and TE cells in blastocysts in the indicated groups. The nuclei of ICM and TE cells were stained with Hoechst (blue) and PI (red) dye, respectively. Bar $=50 \mu \mathrm{m}$. (A, bottom) Apoptosis detection analysis using blastocysts of the indicated groups. Merged images between TUNEL (green, white arrow) and DAPI (blue) signals are shown. Bar $=50 \mu \mathrm{m}$. (B) The rate of fusion, cleavage and blastocyst formation. In total, 664 embryos were used. (C) Quantification of total cell numbers in the blastocysts including ICM and TE cells of the

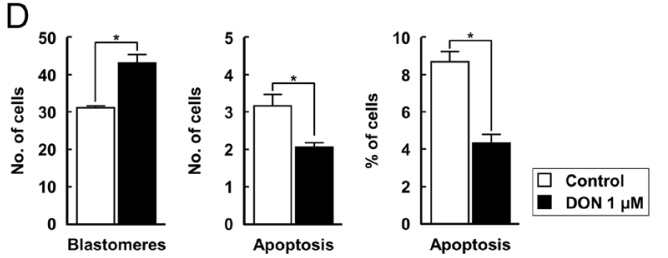
indicated groups. In total, 64 blastocysts were used. (D) Quantification of the numbers and proportions of apoptotic cells in the indicated groups. In total, 64 blastocysts were used. The data are from at least three independent experiments and the values represent the means \pm S.E.M. $(* P<0.05)$.

In addition, the number and percentage of apoptotic cell in blastocysts was significantly decreased in $1 \mu \mathrm{M}$ DON-treated group $(2.1 \pm 0.1$ vs $3.2 \pm 0.3$ and $4.3 \pm 0.5$ vs $8.7 \pm 0.5 \%, P<0.05$; Fig. $5 \mathrm{D})$.

\section{Discussion}

In the present study, for the first time, we demonstrated that DON supplementation during the first half period of IVM produced large numbers of developmentally competent MII oocytes by transiently arresting meiosis of immature oocytes. DON (at $1 \mu \mathrm{M}$ ) effectively synchronized nuclear and cytoplasmic maturation of oocytes by maintaining higher intra-oocyte cAMP levels and supported ERK phosphorylation and clear rearrangement of cortical granules in membrane of MII oocytes, showing balanced meiosis progression between nuclear and cytoplasmic maturation. Subsequently, DON improved the developmental competence of embryos after PA, IVF and SCNT. Therefore, $1 \mu \mathrm{M}$ DON can be used to increase the yield of competent MII oocytes by synchronizing nuclear/cytoplasmic maturation.

Growth of oocytes and the regulation of oocyte meiotic maturation are affected by follicular somatic cell compartments such as the granulosa and cumulus cells surrounding the oocyte (Gilchrist et al. 2004). Specifically, cumulus cells and oocyte are connected and communicate with each other by cell-cell communication via gap junctions (Dekel 1988). Small ions, peptides, and other factors could be migrated between oocyte and cumulus cells through gap junction (Funahashi \& Day 1997). Generally, it was known that EGF-like peptides (Downs \& Chen 2008), amino acids (Colonna \& Mangia
1983), glucose metabolites, purines/pyrimidines and cAMP (Sutton et al. 2003) are transferred from cumulus cells to oocytes via gap-junctional communication. Therefore, cumulus cell-oocyte gap junction coupling is important for oocyte maturation and a key component of oocyte developmental competence (Gilchrist et al. 2004). Among the many factors, CAMP has the important role in the regulation of meiosis of oocytes. Maintaining the relatively greater concentrations of CAMP in the oocyte is required for sustaining oocytes in the meiotic-arrested state for proper maturation of oocytes (Albuz et al. 2010), as precocious meiotic resumption could be begun by a decrease in CAMP concentration (Ramos Leal et al. 2018). Naturally, pre-ovulatory LH surge induces a decrease in intra-oocyte cAMP by the breakdown of gap junctions between the oocyte and granulosa cells, and it allows for the resumption of meiosis (Eppig 1991). Therefore, many researchers have tried to improve the quality of MII oocytes by adding the cAMP regulators, such as PDE inhibitors or dbcAMP, into collection or IVM medium to prevent spontaneous meiosis activation (Gilchrist et al. 2016). Various types of PDE inhibitors have been used to improve porcine IVM, including nonspecific (IBMX) (Kawashima et al. 2008), PDE3-specific (cilostamide) (Dieci et al. 2013) or PDE4specific inhibitors (Rolipram) (Laforest et al. 2005). In addition, supplementation of IBMX into porcine COC collection medium has been tried (Appeltant et al. 2015) to prevent spontaneous meiotic resumption by physical stimulation (Funahashi \& Day 1997).

Another way to sustain higher concentrations of intra-oocyte cAMP might be the use of an inhibitor of hyaluronan synthesis, DON. Yokoo and Sato (2004) 
suggested that the haluronan-CD44 interaction during cumulus expansion induces disruption of the $\mathrm{Cx} 43$ gap junction in the COCs, which inhibits the transport of cAMP from cumulus cells into oocytes and thereby leads to precocious meiotic resumption of oocytes. Therefore, transient inhibition of cumulus expansion by DON might be helpful for keeping the gap junction open and leading to continuously introducing cumulus cell-origin cAMP into oocytes. Previously, it was reported that no evidence of porcine cumulus expansion was shown, when DON was supplemented during the culture period of IVM (Yokoo et al. 2010). Based on this scheme, we assumed that the developmental competence of oocyte matured in vitro could be enhanced by mimicking active communication between the oocyte and follicular cells, which is induced by DON supplementation during initiation of maturation. Therefore, we investigated the effects of DON supplementation during the first half period of IVM on oocyte nuclear and cytoplasmic maturation and subsequent embryo development.

In the present study, although oocytes matured with $10 \mu \mathrm{M}$ DON showed significant higher proportions of GV stage after $22 \mathrm{~h}$ of IVM, only $1 \mu \mathrm{M}$ DON group showed significantly increased MII rate compared to other groups at the end of IVM culture. Based on nuclear maturation rate at the end of IVM, $1 \mu \mathrm{M}$ DON supplementation during the first half period of IVM was suggested to be optimal for porcine IVM and used for further investigation. To clarify meiotic arrest activity of DON, meiosis progression was assessed after 3, 6 , and $9 \mathrm{~h}$ of IVM. No differences in GV stage arrest were found after $3 \mathrm{~h}$ and $9 \mathrm{~h}$ of IVM. However, at $6 \mathrm{~h}$ of IVM, oocytes matured with DON showed significant increase in GV stage. This result suggested that activity of DON might be closely associated with GV to GVBD transition, particularly at $6 \mathrm{~h}$ of IVM. To investigate how DON exerted meiotic arrest activity, the concentration of cAMP was assessed after 6,22 , and $44 \mathrm{~h}$ of IVM, as maintaining higher CAMP concentration is required for meiotic arrest (Bilodeau-Goeseels 2011). At 6 h of IVM, the concentration of cAMP in DON treatment group was significantly higher than control group, supporting meiotic arrest activity of DON found at $6 \mathrm{~h}$. Furthermore, these changes could be supported by increased pAKT/ AKT ratio and PKA-associated transcripts expression (PRKAR1A and PRKACA) in oocytes matured with DON. In porcine oocyte, it was reported that AKT signaling is constantly detected in oocytes during IVM and involved in meiotic progression (Kalous et al. 2009). PKA, CAMP-dependent protein kinase, is the main effector of cAMP signaling in all tissues (Berthon et al. 2015) and composed of the regulatory (PRKAR1A) and catalytic (PRKACA) subunits (Tseng et al. 2017). AKT- and PKAmediated phosphorylation of PDE3A is required for resumption of meiosis by hydrolyzing CAMP (Han et al. 2006). Therefore, the increase in PAKT/AKT ratio and PKA-associated transcripts (PRKAR1A and PRKACA) might be due to demand for high activity of PDE3A to control intra-oocyte cAMP levels increased by DON.

In terms of cytoplasmic maturation of oocytes, several direct parameters, including ERK phosphorylation and cortical granule rearrangement, were reported. ERK phosphorylation at MII stage is characterized as a parameter of cytoplasmic maturation (Popelkova et al. 2006). No ERK phosphorylation was observed at the GV stage, whereas it gradually increased until MI and MII stages (Song et al. 2018). Treatment of ERK inhibitors, such as PD98059 and U0126, during IVM prevented meiosis progression in COCs (Fan et al. 2003, Meinecke \& Krischek 2003) and caused abnormal spindle formation (Lee et al. 2007), suggesting that ERK phosphorylation kinetics may be involved in dynamics of cytoskeleton proteins. The results in the present study revealed that ERK1/2 phosphorylation was retarded with DON treatment until $22 \mathrm{~h}$ of IVM, whereas phosphorylation of ERK1/2 in MII oocytes was significantly increased at $44 \mathrm{~h}$ of IVM, suggesting DON improved cytoplasmic maturation at the end of IVM. In addition, another criterion for cytoplasmic maturation is cortical granule rearrangement (Liu et al. 2005). The peanut agglutinin was reported to be a reliable molecular probe for microscopic visualization of cortical granules in pig oocytes (Yoshida et al. 1993), as peanut agglutinin lectin specifically binds with sugars on mammalian cortical granules (Ducibella et al. 1990, Long et al. 1994). The present study showed that both left and right thickness of lectin in $1 \mu \mathrm{M}$ DON-treated oocytes was significantly decreased at $44 \mathrm{~h}$ of IVM, indicating that rearrangement of cortical granules in MII oocytes was increased. Furthermore, distributions of mitochondria and actin filaments in MII oocytes, two key indexes of cytoplasmic maturation of oocytes (Sun et al. 2001, Sha et al. 2010), were investigated. In the present study, DON treatment significantly increased diffuse mitochondrial distribution and decreased semi-peripheral mitochondrial distribution, indicating that cytoplasmic maturation of oocytes was improved by DON supplementation during the first half period of IVM. However, there was no significant difference in distribution of actin filaments between control and DON treatment groups. It might be because control group already had high normal actin distribution (83.3\%). Based on these results, it was demonstrated that DON-assisted IVM improved cytoplasmic maturation of oocytes through fine-tuning of ERK phosphorylation kinetics, cortical granule rearrangement and mitochondrial distribution. Furthermore, cytoplasmic maturation of oocytes can be assessed by indirect parameters, including monospermic fertilization, blastocyst formation rate, total cell numbers, and cellular survival in blastocysts. The present study showed that $1 \mu \mathrm{M}$ DON treatment during the first half of IVM period led to the improvements in these indirect parameters for cytoplasmic maturation after PA, IVF and SCNT. Therefore, supplementation of DON at optimal 
concentration $(1 \mu \mathrm{M})$ significantly improved direct and indirect parameters of cytoplasmic maturation of oocytes.

In conclusion, DON is demonstrated to be a useful supplement during the first half period of porcine IVM by balancing between nuclear and cytoplasmic maturation. Furthermore, the present study provides the first line of evidence that DON supplementation improves the direct and indirect parameters for cytoplasmic maturation, such as ERK phosphorylation, cortical granule rearrangement, monospermic fertilization, blastocyst formation rate, total cell numbers, and cellular survival in blastocysts. These findings may contribute to our understanding of the mechanisms of oocyte maturation and be useful for improving porcine IVM by providing oocytes with more appropriate culture environments.

\section{Supplementary materials}

This is linked to the online version of the paper at https://doi.org/10.1530/REP-19-0235.

\section{Declaration of interest}

The authors declare that there is no conflict of interest that could be perceived as prejudicing the impartiality of the research reported.

\section{Funding}

This study was supported by grants from the KRIBB Research Initiative Program (KGM4251824) and the Bio \& Medical Technology Development Program through the National Research Foundation of Korea (NRF) funded by the Ministry of Education, Science and Technology (MEST) (No. 2018M3A9H1023142), Republic of Korea.

\section{Author contribution statement}

H-J Y, S L and B-W S conceived the study, carried out the experiments, and then performed the statistical analysis and drafted the manuscript. P-S J, S-A C, Y-H P, B-S S, S-B Y, P K, K-J J, Y-H K, J-W H, S-R L, D-B K and Y-K C assisted the project and revised the manuscript. J-S K and S-U K supervised the research and supplied the funding. All authors read, revised, and approved the final manuscript.

\section{References}

Aigner B, Renner S, Kessler B, Klymiuk N, Kurome M, Wunsch A \& Wolf E 2010 Transgenic pigs as models for translational biomedical research. Journal of Molecular Medicine 88 653-664. (https://doi.org/10.1007/ s00109-010-0610-9)

Albuz FK, Sasseville M, Lane M, Armstrong DT, Thompson JG \& Gilchrist RB 2010 Simulated physiological oocyte maturation (SPOM): a novel in vitro maturation system that substantially improves embryo yield and pregnancy outcomes. Human Reproduction 25 2999-3011. (https://doi.org/10.1093/humrep/deq246)

Appeltant R, Beek J, Vandenberghe L, Maes D \& Van Soom A 2015 Increasing the CAMP concentration during in vitro maturation of pig oocytes improves cumulus maturation and subsequent fertilization in vitro. Theriogenology 83 344-352. (https://doi.org/10.1016/j. theriogenology.2014.09.023)

Bates CJ, Adams WR \& Handschumacher RE 1966 Control of the formation of uridine diphospho-N-acetyl-hexosamine and glycoprotein synthesis in rat liver. Journal of Biological Chemistry 241 1705-1712.

Beebe LF, Mcllfatrick SJ \& Nottle MB 2009 Cytochalasin B and trichostatin A treatment postactivation improves in vitro development of porcine somatic cell nuclear transfer embryos. Cloning and Stem Cells $11477-$ 482. (https://doi.org/10.1089/clo.2009.0029)

Berthon AS, Szarek E \& Stratakis CA 2015 PRKACA: the catalytic subunit of protein kinase A and adrenocortical tumors. Frontiers in Cell and Developmental Biology 3 26. (https://doi.org/10.3389/fcell.2015.00026)

Betthauser J, Forsberg E, Augenstein M, Childs L, Eilertsen K, Enos J, Forsythe T, Golueke P, Jurgella G, Koppang R et al. 2000 Production of cloned pigs from in vitro systems. Nature Biotechnology 18 1055-1059. (https://doi.org/10.1038/80242)

Bilodeau-Goeseels S 2011 Cows are not mice: the role of cyclic AMP, phosphodiesterases, and adenosine monophosphate-activated protein kinase in the maintenance of meiotic arrest in bovine oocytes. Molecular Reproduction and Development 78 734-743. (https://doi.org/10.1002/ mrd.21337)

Chen L, Wert SE, Hendrix EM, Russell PT, Cannon M \& Larsen WJ 1990 Hyaluronic acid synthesis and gap junction endocytosis are necessary for normal expansion of the cumulus mass. Molecular Reproduction and Development 26 236-247. (https://doi.org/10.1002/mrd.1080260307)

Colonna R \& Mangia F 1983 Mechanisms of amino acid uptake in cumulusenclosed mouse oocytes. Biology of Reproduction 28 797-803. (https:// doi.org/10.1095/biolreprod28.4.797)

Dekel N 1988 Spatial relationship of follicular cells in the control of meiosis. Progress in Clinical and Biological Research 267 87-101.

Dieci C, Lodde V, Franciosi F, Lagutina I, Tessaro I, Modina SC, Albertini DF, Lazzari G, Galli C \& Luciano AM 2013 The effect of cilostamide on gap junction communication dynamics, chromatin remodeling, and competence acquisition in pig oocytes following parthenogenetic activation and nuclear transfer. Biology of Reproduction 89 68. (https:// doi.org/10.1095/biolreprod.113.110577)

Downs SM \& Chen J 2008 EGF-like peptides mediate FSH-induced maturation of cumulus cell-enclosed mouse oocytes. Molecular Reproduction and Development 75 105-114. (https://doi.org/10.1002/mrd.20781)

Ducibella T, Kurasawa S, Rangarajan S, Kopf GS \& Schultz RM 1990 Precocious loss of cortical granules during mouse oocyte meiotic maturation and correlation with an egg-induced modification of the zona pellucida. Developmental Biology 137 46-55. (https://doi. org/10.1016/0012-1606(90)90006-5)

Elahi F, Lee H, Lee Y, Park B, Lee J, Hyun SH \& Lee E 2016 Cilostazol improves developmental competence of pig oocytes by increasing intraoocyte cyclic adenosine monophosphate level and delaying meiotic resumption. Reproduction in Domestic Animals 51 220-226. (https:// doi.org/10.1111/rda.12669)

Eppig JJ 1991 Intercommunication between mammalian oocytes and companion somatic cells. BioEssays 13 569-574. (https://doi. org/10.1002/bies.950131105)

Fan HY, Tong C, Lian L, Li SW, Gao WX, Cheng Y, Chen DY, Schatten H \& Sun QY 2003 Characterization of ribosomal S6 protein kinase p90rsk during meiotic maturation and fertilization in pig oocytes: mitogen-activated protein kinase-associated activation and localization. Biology of Reproduction $\mathbf{6 8}$ 968-977. (https://doi.org/10.1095/biolreprod.102.008839)

Funahashi H \& Day BN 1997 Advances in in vitro production of pig embryos. Journal of Reproduction and Fertility: Supplement 52 271-283.

Funahashi H, Cantley TC \& Day BN 1997 Synchronization of meiosis in porcine oocytes by exposure to dibutyryl cyclic adenosine monophosphate improves developmental competence following in vitro fertilization. Biology of Reproduction 57 49-53. (https://doi.org/10.1095/ biolreprod57.1.49)

Galli C, Lagutina I, Perota A, Colleoni S, Duchi R, Lucchini F \& Lazzari G 2012 Somatic cell nuclear transfer and transgenesis in large animals: current and future insights. Reproduction in Domestic Animals 47 (Supplement 3) 2-11. (https://doi.org/10.1111/j.14390531.2012.02045.x)

Gilchrist RB, Ritter LJ \& Armstrong DT 2004 Oocyte-somatic cell interactions during follicle development in mammals. Animal Reproduction Science 82-83 431-446 . (https://doi.org/10.1016/j. anireprosci.2004.05.017) 
Gilchrist RB, Luciano AM, Richani D, Zeng HT, Wang X, Vos MD, Sugimura S, Smitz J, Richard FJ \& Thompson JG 2016 Oocyte maturation and quality: role of cyclic nucleotides. Reproduction 152 R143-R157. (https://doi.org/10.1530/REP-15-0606)

Grupen CG, Fung M \& Armstrong DT 2006 Effects of milrinone and butyrolactone-I on porcine oocyte meiotic progression and developmental competence. Reproduction, Fertility, and Development 18 309-317. (https://doi.org/10.1071/rd05125)

Hall V, Hinrichs K, Lazzari G, Betts DH \& Hyttel P 2013 Early embryonic development, assisted reproductive technologies, and pluripotent stem cell biology in domestic mammals. Veterinary Journal 197 128-142. (https://doi.org/10.1016/j.tvjl.2013.05.026)

Han SJ, Vaccari S, Nedachi T, Andersen CB, Kovacina KS, Roth RA \& Conti M 2006 Protein kinase B/Akt phosphorylation of PDE3A and its role in mammalian oocyte maturation. EMBO Journal 25 5716-5725. (https://doi.org/10.1038/sj.emboj.7601431)

Kalous J, Kubelka M, Solc P, Susor A \& Motlik J 2009 AKT (protein kinase B) is implicated in meiotic maturation of porcine oocytes. Reproduction 138 645-654. (https://doi.org/10.1530/REP-08-0461)

Kawashima I, Okazaki T, Noma N, Nishibori M, Yamashita Y \& Shimada M 2008 Sequential exposure of porcine cumulus cells to $\mathrm{FSH}$ and/or $\mathrm{LH}$ is critical for appropriate expression of steroidogenic and ovulation-related genes that impact oocyte maturation in vivo and in vitro. Reproduction 136 9-21. (https://doi.org/10.1530/REP-08-0074)

Kim JS, Chae JI, Song BS, Lee KS, Choo YK, Chang KT, Park H \& Koo DB 2010 Iloprost, a prostacyclin analogue, stimulates meiotic maturation and early embryonic development in pigs. Reproduction, Fertility, and Development 22 437-447. (https://doi.org/10.1071/RD08287)

Krisher RL 2004 The effect of oocyte quality on development. Journal of Animal Science 82 (E-Supplement) E14-E23. (https://doi. org/10.2527/2004.8213_supplE14x)

Laforest MF, Pouliot E, Gueguen L \& Richard FJ 2005 Fundamental significance of specific phosphodiesterases in the control of spontaneous meiotic resumption in porcine oocytes. Molecular Reproduction and Development 70 361-372. (https://doi.org/10.1002/mrd.20203)

Lee SE, Kim JH \& Kim NH 2007 Inactivation of MAPK affects centrosome assembly, but not actin filament assembly, in mouse oocytes maturing in vitro. Molecular Reproduction and Development 74 904-911. (https:// doi.org/10.1002/mrd.20695)

Liu XY, Mal SF, Miao DQ, Liu DJ, Bao S \& Tan JH 2005 Cortical granules behave differently in mouse oocytes matured under different conditions. Human Reproduction 20 3402-3413. (https://doi.org/10.1093/humrep/ dei265)

Lodde V, Franciosi F, Tessaro I, Modina SC \& Luciano AM 2013 Role of gap junction-mediated communications in regulating large-scale chromatin configuration remodeling and embryonic developmental competence acquisition in fully grown bovine oocyte. Journal of Assisted Reproduction and Genetics 30 1219-1226. (https://doi.org/10.1007/ s10815-013-0061-7)

Long CR, Damiani P, Pinto-Correia C, MacLean RA, Duby RT \& Robl JM 1994 Morphology and subsequent development in culture of bovine oocytes matured in vitro under various conditions of fertilization. Journal of Reproduction and Fertility 102 361-369. (https://doi.org/10.1530/ jrf.0.1020361)

Luciano AM, Pocar P, Milanesi E, Modina S, Rieger D, Lauria A \& Gandolfi F 1999 Effect of different levels of intracellular cAMP on the in vitro maturation of cattle oocytes and their subsequent development following in vitro fertilization. Molecular Reproduction and Development 54 8691. (https://doi.org/10.1002/(SICl)1098-2795(199909)54:1<86::AIDMRD13>3.0.CO;2-C)

Luciano AM, Modina S, Vassena R, Milanesi E, Lauria A \& Gandolfi F 2004 Role of intracellular cyclic adenosine 3',5'-monophosphate concentration and oocyte-cumulus cells communications on the acquisition of the developmental competence during in vitro maturation of bovine oocyte. Biology of Reproduction 70 465-472. (https://doi. org/10.1095/biolreprod.103.020644)

Luo Y, Lin L, Bolund L, Jensen TG \& Sorensen CB 2012 Genetically modified pigs for biomedical research. Journal of Inherited Metabolic Disease 35 695-713. (https://doi.org/10.1007/s10545-012-9475-0)

Mayes MA \& Sirard MA 2002 Effect of type 3 and type 4 phosphodiesterase inhibitors on the maintenance of bovine oocytes in meiotic arrest. Biology of Reproduction 66 180-184. (https://doi.org/10.1095/ biolreprod66.1.180)
McCarty MF 1996 Glucosamine for wound healing. Medical Hypotheses 47 273-275. (https://doi.org/10.1016/s0306-9877(96)90066-3)

Meinecke B \& Krischek C 2003 MAPK/ERK kinase (MEK) signalling is required for resumption of meiosis in cultured cumulusenclosed pig oocytes. Zygote 11 7-16. (https://doi.org/10.1017/ S0967199403001023)

Nagashima $H$, Fujimura T, Takahagi $Y$, Kurome M, Wako N, Ochiai T, Esaki R, Kano K, Saito S, Okabe M et al. 2003 Development of efficient strategies for the production of genetically modified pigs. Theriogenology 59 95-106. (https://doi.org/10.1016/s0093-691x(02)01261-x)

Ponderato N, Crotti G, Turini P, Duchi R, Galli C \& Lazzari G 2002 Embryonic and foetal development of bovine oocytes treated with a combination of butyrolactone I and roscovitine in an enriched medium prior to IVM and IVF. Molecular Reproduction and Development 62 513-518. (https://doi.org/10.1002/mrd.10134)

Popelkova M, Sirotkin AV, Bezakova A, Makarevic A, Pivko J, Kacmarik J \& Kovac G 2006 Effect of IGF-I, leptin, ghrelin and MAPK-ERK on the nuclear maturation of bovine oocytes. Bulletin of the Veterinary Institute in Pulawy $\mathbf{5 0} 179$.

Prather RS, Hawley RJ, Carter DB, Lai L \& Greenstein JL 2003 Transgenic swine for biomedicine and agriculture. Theriogenology 59 115-123. (https://doi.org/10.1016/s0093-691x(02)01263-3)

Ramos Leal G, Santos Monteiro CA, Souza-Fabjan JMG, de Paula Vasconcelos CO, Garcia Nogueira LA, Reis Ferreira AM \& Varella Serapiao R 2018 Role of cAMP modulator supplementations during oocyte in vitro maturation in domestic animals. Animal Reproduction Science 199 1-14. (https://doi.org/10.1016/j.anireprosci.2018.11.002)

Richter A, Kurome M, Kessler B, Zakhartchenko V, Klymiuk N, Nagashima H, Wolf E \& Wuensch A 2012 Potential of primary kidney cells for somatic cell nuclear transfer mediated transgenesis in pig. BMC Biotechnology 12 84. (https://doi.org/10.1186/1472-6750-12-84)

Sha W, Xu BZ, Li M, Liu D, Feng HL \& Sun QY 2010 Effect of gonadotropins on oocyte maturation in vitro: an animal model. Fertility and Sterility $\mathbf{9 3}$ 1650-1661. (https://doi.org/10.1016/j.fertnstert.2009.03.003)

Song BS, Jeong PS, Lee JH, Lee MH, Yang HJ, Choi SA, Lee HY, Yoon SB, Park YH, Jeong KJ et al. 2018 The effects of kinase modulation on in vitro maturation according to different cumulus-oocyte complex morphologies. PLOS ONE 13 e0205495. (https://doi.org/10.1371/ journal.pone.0205495)

Sun QY, Wu GM, Lai L, Park KW, Cabot R, Cheong HT, Day BN, Prather RS \& Schatten H 2001 Translocation of active mitochondria during pig oocyte maturation, fertilization and early embryo development in vitro. Reproduction 122 155-163. (https://doi. org/10.1530/rep.0.1220155)

Sutton ML, Gilchrist RB \& Thompson JG 2003 Effects of in-vivo and in-vitro environments on the metabolism of the cumulus-oocyte complex and its influence on oocyte developmental capacity. Human Reproduction Update 9 35-48. (https://doi.org/10.1093/humupd/dmg009)

Tseng IC, Huang WJ, Jhuang YL, Chang YY, Hsu HP \& Jeng YM 2017 Microinsertions in PRKACA cause activation of the protein kinase A pathway in cardiac myxoma. Journal of Pathology 242 134-139. (https:// doi.org/10.1002/path.4899)

Yokoo M \& Sato E 2004 Cumulus-oocyte complex interactions during oocyte maturation. International Review of Cytology 235 251-291. (https://doi.org/10.1016/S0074-7696(04)35006-0)

Yokoo M, Kimura N \& Sato E 2010 Induction of oocyte maturation by hyaluronan-CD44 interaction in pigs. Journal of Reproduction and Development 56 15-19. (https://doi.org/10.1262/jrd.09-173e)

Yoshida M, Cran DG \& Pursel VG 1993 Confocal and fluorescence microscopic study using lectins of the distribution of cortical granules during the maturation and fertilization of pig oocytes. Molecular Reproduction and Development 36 462-468. (https://doi.org/10.1002/ mrd.1080360409)

Received 28 May 2019

First decision 14 June 2019

Revised manuscript received 22 October 2019

Accepted 25 October 2019 